\title{
Remote Examination and Screening for Domestic Abuse. Comment on "Online Antenatal Care During the COVID-19 Pandemic: Opportunities and Challenges"
}

\author{
Hannah Lee Grimes* , BA; Ramnik Uppal*, BA \\ University of Cambridge Clinical School, Cambridge, United Kingdom \\ *all authors contributed equally
}

Corresponding Author:

Hannah Lee Grimes, BA

University of Cambridge Clinical School

Hills Road

Cambridge

United Kingdom

Phone: 4401223336700

Email: $\underline{\text { hlg42@cam.ac.uk }}$

Related Article:
Comment on: https://www.jmir.org/2020/7/e19916/

(J Med Internet Res 2021;23(2):e23295) doi: 10.2196/23295

\section{KEYWORDS}

spouse abuse; domestic abuse; apps; patient information; antenatal care; COVID-19

After reading the viewpoint by $\mathrm{Wu}$ et al [1] on opportunities for the delivery of antenatal care online during the COVID-19 pandemic, we would like to draw attention to a potential further aspect of this analysis. The authors surveyed 983 Chinese pregnant women and concluded that online antenatal care is likely to be an effective alternative for pregnant women, enabling them to access basic care without attending the hospital[1]. This is optimal with regards to minimizing the infection risk during the pandemic. However, it is important to remember that for a proportion of women, these antenatal visits provide a critical opportunity for physicians to screen for domestic abuse.

A cross-sectional study, also assessing a population of Chinese pregnant women, found that $15.62 \%$ of their subjects were identified as victims of domestic abuse [2]. Data released by the World Health Organization suggest that the number of women affected by domestic violence during pregnancy may be between $1 \%$ and $28 \%$ [3]. This proportion is by no means negligible.

In many countries, antenatal screening for domestic abuse when consulting with the patient is sporadic. One study of Canadian doctors found that $33 \%$ of professionals surveyed "never or only rarely" asked women about domestic abuse during antenatal appointments [4]. Provision of antenatal care online could result in even fewer women being able to confide in their doctor and receive much-needed assistance with respect to abusive situations at home. This might be due to women feeling less able to seek help through an online service compared to face-to-face consultations.

The COVID-19 pandemic has complicated this situation further. The London metropolitan police reported that since lockdowns were introduced in the United Kingdom, 380 more calls per week related to domestic abuse have been recorded [5]. Unpacking this data further, it is noteworthy that the majority of these reports of abuse were from third-party callers, perhaps due to the increased presence of neighbors [5]. This suggests that while there may be a potential surge in domestic abuse due to lockdown restrictions, this may not be associated with an increased probability of victims reporting the crime.

We suggest that to best address this gap in their proposal, $\mathrm{Wu}$ et al [1] should factor in how their proposed online antenatal care delivery system could incorporate adaptations to provide help to victims without compromising their safety. One possible method of achieving this could be to add a layer to any application developed through which women could find support numbers for relevant domestic abuse charities or alert their doctor to their need for a face-to-face appointment to discuss their home situation. It is important for this feature to be sufficiently blended into the app such that it would not alert suspicion from the perpetrator and thus compromise the safety of any woman seeking help. 


\section{Editorial Notice}

The corresponding author of "Online Antenatal Care During the COVID-19 Pandemic: Opportunities and Challenges" did not respond to our invitation to reply to this commentary.

\section{Conflicts of Interest}

None declared.

\section{References}

1. Wu H, Sun W, Huang X, Yu S, Wang H, Bi X, et al. Online Antenatal Care During the COVID-19 Pandemic: Opportunities and Challenges. J Med Internet Res 2020 Jul 22;22(7):e19916 [FREE Full text] [doi: 10.2196/19916] [Medline: 32658860]

2. Zheng B, Zhu X, Hu Z, Zhou W, Yu Y, Yin S, et al. The prevalence of domestic violence and its association with family factors: a cross-sectional study among pregnant women in urban communities of Hengyang City, China. BMC Public Health 2020 May 05;20(1):620 [FREE Full text] [doi: 10.1186/s12889-020-08683-9] [Medline: $\underline{32370810]}$

3. Garcia-Moreno C, Jansen HA, Ellsberg M, Heise L, Watts CH. Prevalence of intimate partner violence: findings from the WHO multi-country study on women's health and domestic violence. The Lancet 2006 Oct;368(9543):1260-1269. [doi: 10.1016/S0140-6736(06)69523-8]

4. Long AJ, Golfar A, Olson DM. Screening in the Prenatal Period for Intimate Partner Violence and History of Abuse: A Survey of Edmonton Obstetrician/Gynaecologists. J Obstet Gynaecol Can 2019 Jan;41(1):38-45. [doi: 10.1016/j.jogc.2018.05.003] [Medline: $\underline{30585166]}$

5. Ivandic R, Kirchmaier T. Home is not a safe place for everyone: domestic abuse between partners increased during lockdown. LSE Covid 19 Blog. 2020 Jun 30. URL: https://blogs.lse.ac.uk/covid19/2020/06/30/ home-is-not-a-safe-place-for-everyone-domestic-abuse-between-current-partners-increased-during-lockdown/ [accessed 2021-02-09]

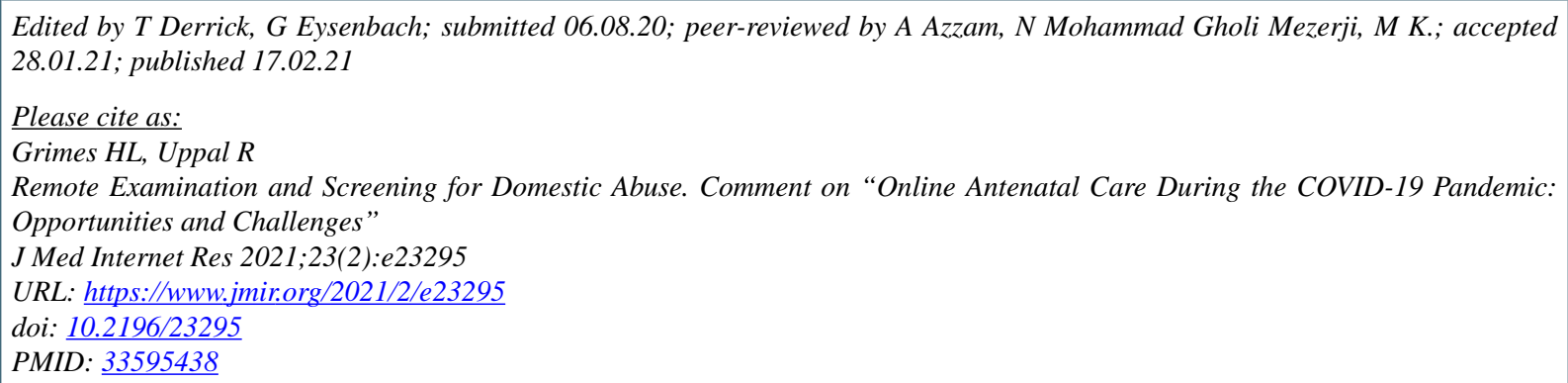

(CHannah Lee Grimes, Ramnik Uppal. Originally published in the Journal of Medical Internet Research (http://www.jmir.org), 17.02.2021. This is an open-access article distributed under the terms of the Creative Commons Attribution License (https://creativecommons.org/licenses/by/4.0/), which permits unrestricted use, distribution, and reproduction in any medium, provided the original work, first published in the Journal of Medical Internet Research, is properly cited. The complete bibliographic information, a link to the original publication on http://www.jmir.org/, as well as this copyright and license information must be included. 